\title{
REGULAMENTAÇÃO LINGUÍSTICA EM E-MAILS INSTITUCIONAIS: CONFLITO ENTRE PROFESSORES UNIVERSITÁRIOS NO AMBIENTE INSTITUCIONAL ${ }^{1}$
}

\author{
Wagner Rodrigues Silva ${ }^{2}$
}

Resumo: Investigo reflexões metalinguísticas realizadas por docentes, ao focalizarem noções de ordem on de regulamentação linguistica, no ambiente de interação virtual, mediado por um programa de e-mail institucional, numa universidade pública. Numa abordagem sociopragmática, o ambiente virtual é caracterizado como um tecido de vozes sociais, as quais sinalizam para o posicionamento dos interactantes no espaço institucional em que estão inseridos. Os dados mostram servidores públicos se apropriando de um artefato tecnológico para interagir num novo espaço: o ambiente profissional virtual. A troca de mensagens eletrônicas parece influenciada por outras interações mediadas por artefatos digitais característicos de ambientes virtuais não profissionais. Nesse novo ambiente, tais interações parecem substituir os relacionamentos profissionais sólidos, característicos das interações presenciais, minimiz̨ando o receio do enfoque de assuntos polêmicos para interlocuções convencionais, como o questionamento da competência profissional dos pares, orientado pela cobrança das convenções linguísticas da escrita formal, em mensagens eletrônicas trocadas no ambiente virtual institucional.

Palavras-chave: Linguistica Aplicada. Escrita. Gênero. Letramento digital.

Nos veussus lá do nordeste

Sou repente sim sinhô

Mesmo escrevendo errado

Pode crer que sou douto

Autoria:

Sivirinu Xique-Xique Mandacaru Aroeira

(Poeta Popular do Nordeste) ${ }^{3}$

\footnotetext{
${ }^{1}$ Este trabalho contribui com as pesquisas desenvolvidas no âmbito do grupo de pesquisa "Práticas de escrita e de reflexão sobre a escrita em diferentes mídias" (CNPq 475305/2010-8/FAPESP 2010/41497-9), coordenado pela Profa. Dra. Inês Signorini (UNICAMP/IEL). Agradeço a Luiz Paulo da Moita Lopes e Roxane Rojo pelos comentários realizados durante a apresentação deste texto no Seminário de Pesquisa Práticas hipermidiáticas na escola/práticas escolares na hipermídia", em 27 de maio de 2011, no Instituto de Estudos da Linguagem - IEL/UNICAMP. Agradeço também a Janete Silva dos Santos pela leitura crítica realizada de uma versão preliminar deste texto. O conteúdo do artigo, porém, é de minha inteira responsabilidade.

2 Professor da Universidade Federal de Tocantins (UFT). Coordenador do Mestrado em Ensino de Língua e Literatura. Bolsista de produtividade do CNPq. Doutor em Linguística Aplicada (UNICAMP). Email: wagnerodriguesilva@hotmail.com.
} 


\section{INTRODUÇÃO}

Neste trabalho, investigo reflexões metalinguísticas realizadas por professores universitários, ao tematizarem noções de ordem ou de regulamentação linguística, num ambiente de interação virtual, mediado por um programa de e-mail institucional, numa universidade pública brasileira. Para justificar a relevância desta pesquisa, destaco, conforme Paiva (2004, p. 89), que, "como todo sistema complexo", o gênero e-mail "é um sistema aberto e novas possibilidades de gerenciamento e de produção de texto podem surgir. Consequentemente, novas mudanças no comportamento discursivo poderão acontecer". Com seus diferentes matizes, os e-mails se configuram, portanto, como dados significativos para os cientistas da linguagem.

Meu interesse pelas reflexões metalinguísticas se justifica por a interação virtual instaurada reproduzir a organização do "espaço social" (BOURDIEU, 2001) do ambiente presencial, orientada pela dinâmica do mercado produtor regional autorregulado ${ }^{4}$. Essa dinâmica faz-me lembrar da tensão tradicional entre as denominadas ciências naturais e as ciências sociais, provocada pelo paradigma positivista 5 . O mercado local parece refletir a mesma lógica do mercado nacional, cuja economia é fortemente abastecida pela produção e pelo consumo de produtos agropecuários, repercutindo diretamente nas políticas públicas de fomento a pesquisas científicas, nas universidades públicas brasileiras.

\footnotetext{
${ }^{3}$ Dedico este artigo ao "Poeta Popular do Nordeste", Sivirinu Xique-Xique Mandacaru Aroeira (in memoriam), importante personagem nos dados de pesquisa aqui analisados. Durante o processo de avaliação deste artigo, o inesquecível amigo, meu conterrâneo, inesperadamente faleceu, deixando, contudo, boas lembranças na memória dos colegas de trabalho.

${ }^{4}$ Conforme Bourdieu, retomado por Mey (2001, p. 119), "a tarefa do mercado é ser um mediador entre o produtor e o consumidor e permitir que se fixe um preço para as mercadorias. Assim como o mercado opera com um princípio subjacente de racionalidade econômica, também linguistas e cientistas sociais apelam para os princípios que subjazem às respectivas atividades por eles estudadas, por exemplo, as formas como as pessoas organizam suas esferas de vida social, incluindo-se aí a linguagem e seu uso".

${ }^{5}$ Contrapondo-se ao paradigma positivista, tem-se o denominado paradigma científico emergente, orientador da prática científica pós-moderna. Nos termos de Santos (1995, p. 39), o conhecimento não dualista caracteriza tal paradigma, fundado "na superação das distinções tão familiares e óbvias que até há pouco considerávamos insubstituíveis, tais como natureza/cultura, natural/artificial, vivo/inanimado, mente/matéria, observador/observado, subjetivo/objectivo, colectivo/individual, animal/pessoa".
} 
No campus universitário focalizado, observo, conforme mostrado na análise dos dados adiante, um "campo de forças" (BOURDIEU, 2001), formado pelo conflito velado entre as ciências agrárias e as ciências sociais, com especialistas representando as diferentes áreas do conhecimento.

Interessa-me ainda investigar como os docentes refletem sobre os usos das formas linguísticas, considerando as ações provocadas sobre os próprios interactantes, por tais reflexões durante a troca de mensagens eletrônicas no ambiente institucional virtual. Em outras palavras, investigo as atividades metalinguísticas ou metaenunciativas produzidas pelos agentes da interação focalizada. Ao falarem sobre alguns elementos da própria interação virtual em que estão inseridos, os docentes acionam noções de "ordem" ou de "regulamentação linguística" para desqualificar profissionais atuantes em disciplinas ou áreas do conhecimento configuradas como adversárias no espaço universitário em que estão inseridos. Nos termos propostos por Signorini (2002, p. 94), essas noções são aqui concebidas "enquanto configuração sempre transitória do que, no jogo sociocomunicativo e também político e ideológico das relações sociais, se constrói como divisão, borda, ou fronteira nos usos da língua".

Numa abordagem sociopragmática, concebo a língua, de acordo com Mey (2001, p. 102), "como um instrumento de opressão", gerador de conflitos ou embates, visto que pode ser "utilizada pelas classes dominantes para cimentar seu poder". A língua pode ser utilizada como instrumento de opressão, até mesmo por pessoas que não necessariamente ocupam, mas desejam ocupar uma posição de prestígio. Movidas por tal desejo, essas pessoas podem se utilizar de formas linguísticas desprestigiadas, utilizadas por seus adversários, para oprimilos. Nessa perspectiva, o ambiente virtual investigado é caracterizado como um tecido de vozes sociais, as quais expressam o modo como está organizada a posição dos interactantes ou, aproximando-me dos termos utilizados por MEY (2001, p. 80), dos “personagens” com os papéis sociais que lhes são constitutivos ou que desejam assumir. Em outras palavras, os e-mails trocados são realizados em textos, "entendidos como 
a organização coletiva" das vozes da sociedade. O gênero, por sua vez, é aqui concebido como forma relativamente estável, resultante da ação com e sobre a linguagem. É "ação significante", "governada por regras" e "interpretável por meio de convenções” (MILLER, 2009, p. 38).

A universidade pública brasileira ainda se encontra no momento de tentativa de transição paradigmática, marcado pelo esforço de superação da fragmentação disciplinar, o que ainda se configura numa organização espacial em departamentos isolados, dificultando o trabalho cooperativo entre especialistas do conhecimento. Nos termos de Japiassu (2006, p. 21), "as disciplinas se tornam fechadas e estanques, fontes de ciúme, glória, arrogância, poder e atitudes dogmáticas”. Nessa disposição espacial, vigora a distinção valorativa de disciplinas ou áreas do conhecimento sobre outras, concebidas como menos rentáveis na sociedade capitalista, preocupada "exclusivamente com seu lucro sempre renovado e com sua busca incansável e insaciável de rentabilidade" (JAPIASSU, 2006, p. 105).

Feito esse apanhado inicial, para melhor situar o trabalho, além da Introdução, Considerações finais e Referências, este artigo está organizado em três principais seções: Ambiente profissional virtual; Especificidades do gênero email; Embate na escrita universitária. $\mathrm{Na}$ primeira seção, caracterizo o contexto virtual imediato em que se instauram as trocas de mensagens eletrônicas, considerando as relações de força existentes no espaço institucional. $\mathrm{Na}$ segunda seção, apresento uma síntese de alguns estudos linguísticos sobre a escrita digital nos gêneros eletrônicos, destacando duas teses sobre o gênero e-mail, trabalhadas nos referidos estudos, a saber: (1) o e-mail é produto e desencadeador de transformações nas relações humanas; e (2) a escrita do e-mail possui uma informalidade própria. $\mathrm{Na}$ terceira seção, apresento uma análise das reflexões metalinguísticas realizadas no embate travado entre professores universitários, nas trocas de mensagens eletrônicas, quando reproduzem o mito do único padrão linguístico a ser considerado, independentemente da situação comunicativa instaurada, e mobilizam outros gêneros como respostas às coerções sofridas durante a interação, no ambiente profissional virtual. 


\section{AMBIENTE PROFISSIONAL VIRTUAL}

Os dados investigados neste trabalho são compostos por doze diferentes, sendo todas as mensagens enviadas, por meio de um programa de e-mail institucional, para aproximadamente cento e onze (111) docentes efetivos ${ }^{6}$, pertencentes a um dos campi de uma universidade pública federal, na Região Norte do Brasil. Em algumas dessas mensagens, havia textos anexados, tais como reportagens e poemas, circulação comum em fóruns de discussão assíncronos, caracterizados por "relações continuadas e movidas por interesses comuns" (MARCUSCHI, 2004, p. 27). Esses dados correspondem a um recorte realizado a partir de um banco de dados, em constante atualização, o qual é formado por mensagens eletrônicas geradoras de discussões polêmicas, no ambiente virtual, e trocadas por pessoas com interesses comuns, integrantes de comunidades virtuais.

As mensagens focalizadas foram trocadas durante sete (7) dias (entre 27 de outubro e 02 de novembro de 2010), perpassando os quatro dias anteriores e os dois dias posteriores ao segundo turno da eleição presidencial brasileira (31 de outubro de 2010), que elegeu a candidata do governo como presidente da república. É necessário mencionar aqui esse fato histórico porque o uso do e-mail institucional para fazer propaganda partidária da referida candidata desencadeou o conflito analisado neste trabalho. Para os interactantes, o e-mail institucional não seria uma extensão da universidade pública, instituição com a qual se comprometeram no exercício das suas funções. $O$ deslocamento enunciativo possível, a partir do uso do e-mail institucional, enquanto ambiente virtual, pode justificar a quebra das regras ou práticas que compõem o código moral compartilhado pelos servidores públicos.

\footnotetext{
${ }^{6}$ Esses números correspondem aos dados de 13 de maio de 2011. Provavelmente, o quantitativo de docentes não é o mesmo da época em que circularam as mensagens aqui investigadas. Nos últimos anos, as universidades federais, principalmente as localizadas na Região Norte, têm vivenciado um fluxo bastante significativo de entrada e saída de docentes. Esse fluxo é motivado pelo número significativo de concursos abertos para formação do corpo docente das universidades, em especial das novas instituições, criadas com a política governamental de expansão do ensino público superior brasileiro. As dificuldades características da Região Norte também são responsáveis pela intensificação desse fluxo.
}

SILVA - Regulamentação linguística em e-mails institucionais... 
Reproduzo, nos exemplos 1 e 2, as duas primeiras mensagens eletrônicas que provocaram o conflito aqui focalizado. Os nomes próprios aqui utilizados nas mensagens eletrônicas são fictícios. Justifico essa opção para evitar a exposição dos autores das mensagens trocadas 7 . As duas mensagens reproduzidas adiante representam os posicionamentos contrários assumidos pelos docentes diante do uso do programa de e-mail institucional. Tais posicionamentos representam as duas partes componentes do "espaço social", mencionado na introdução deste trabalho e caracterizado aqui como "um espaço de diferenças, no qual as classes existem de algum modo em estado virtual, pontilhadas" (BOURDIEU, 2001, p. 27):

\author{
Exemplo $1-1^{\circ}$ E-mail \\ Amigos, \\ que era a educação no governo Serra em São Paulo. \\ Att \\ Paulo \\ Exemplo $2-2^{\circ}$. E-mail \\ Ok, o que fazemos com email indesejáveis? SPAM! \\ Boas discussões. \\ Profa. Clara Maria Sousa Silva
}

divulgem reportagens anexadas. Elas falam um pouco sobre o

No campus universitário focalizado, esse estado virtual se materializa na disposição dos cursos em localidades distintas. Refiro-me a um campus subdividido em dois outros campi, os quais são tradicionalmente identificados como campus dos cursos de licenciatura e campus das ciências agrárias. O primeiro campus está localizado próximo ao centro da cidade. O nome é justificado pela tradição das primeiras licenciaturas implementadas. Com a adesão da instituição ao "Programa de Apoio a Planos de Reestruturação e Expansão das Universidades Federais (Reuni)", novas licenciaturas e alguns cursos tecnológicos foram criados. Neste

\footnotetext{
7 Aproveito o ensejo para agradecer aos docentes pela autorização para uso das mensagens eletrônicas na pesquisa aqui apresentada. Sem a autorização desses profissionais, não poderia realizar este trabalho. A versão final deste artigo foi lida por esses docentes. Após a leitura, confirmaram a autorização feita previamente.
} 
campus há apenas uma pós-graduação stricto sensu: um mestrado numa área das licenciaturas. O segundo campus está localizado às margens de uma BR, na zona rural da cidade. Possui dois cursos de graduação na área de Ciências Agrárias e dois cursos de pós-graduação stricto sensu: um mestrado e um doutorado, também nas Ciências Agrárias. Atualmente, em nível de doutorado, esse é o único curso oferecido em toda a universidade, considerando todos os campi que a compõem. Essa disposição espacial não me parece aleatória, mas reproduz a dinâmica do mercado autorregulado, a qual fortalece antigas dicotomias, como bacharelado/licenciatura; Ciências Agrárias/Ciências Sociais; objetivo/subjetivo; quantitativo/qualitativo. Conforme Bourdieu (2001, p. 50),

todas as sociedades se apresentam como espaços sociais, isto é, estruturas de diferenças que não podemos compreender verdadeiramente a não ser construindo o princípio gerador que funda essas diferenças na objetividade. Princípio que é o da estrutura da distribuição das formas de poder ou dos tipos de capital eficientes no universo social considerado - e que variam, portanto, de acordo com os lugares e os momentos.

No exemplo 1, o leitor encontra o primeiro e-mail enviado à lista de endereços eletrônicos dos docentes. Trata-se do texto produzido por um doutor em História, o qual traz o envolvimento em questões políticas de interesse da instituição como traço identitário do colegiado de que faz parte, Curso de História (Bacharelado e Licenciatura). Esse envolvimento provavelmente motivou o envio da mensagem eletrônica, nos últimos dias da campanha presidencial, quando as pesquisas de intenção de votos sinalizavam uma significativa mudança no cenário da eleição presidencial, resultando na significativa perda de votos pela candidata do governo, atual presidenta da República do Brasil. Em diferentes setores das universidades federais, esse novo cenário significou uma ameaça à continuação da política pública que se consolidava nas universidades, oposta à reforma do Estado realizada pelo governo anterior da República. Conforme esclarece Chauí (2003, p. 6), “essa reforma, ao definir os setores que compõem o Estado, designou um desses setores como setor de serviços não exclusivos do Estado e nele 
colocou a educação, a saúde e a cultura"8. Configura-se, portanto, numa política de fortalecimento da fragmentação da universidade, intensificada pela competição provocada pelas exigências de mercado, impostas principalmente pelas instituições privadas financiadoras de pesquisa.

O exemplo 1 configura-se como uma mensagem bastante informal, sinalizada inicialmente pela escolha lexical do vocativo (Amigos), que interpela diretamente os interlocutores, docentes com os quais o autor da mensagem compartilha um ambiente de trabalho comum. O mesmo padrão de informalidade é mantido pela abreviação da saudação final (Att) e pela assinatura reduzida ao primeiro nome (Paulo). Há omissão de letras, pontuação escassa e uso de recursos morfossintáticos pouco elaborados. Esse texto remete-me às palavras de Violi (2009, p. 55), quando faz referência ao estilo linguístico comum aos e-mails, caracterizado “por um certo 'desleixo' quanto à ortografia e à precisão da digitação, que se combina, pelo lado do leitor, com um grau de tolerância muito alto para grafia e os erros de digitação”.

$\mathrm{O}$ exemplo 2 corresponde à primeira resposta à mensagem inicialmente enviada, exemplo 1, para a lista de e-mails dos docentes. $\mathrm{O}$ texto foi produzido por uma doutora em Cirurgia Veterinária, a qual parece não compartilhar do receio manifestado pelo autor da mensagem eletrônica inicial. Essa mensagem foi tomada como lixo eletrônico, podendo ser agrupada no que Heyd (2004) denomina "folclore digital" (Digital Folklore), ou seja, um tipo de supergênero composto por mensagens encaminhadas para diversos usuários com propósitos diversos, dentre os quais destaco o fortalecimento das redes sociais digitais e a promoção de oportunidades para o comportamento cooperativo. O "folclore digital" é composto por subgêneros do seguinte

\footnotetext{
${ }^{8}$ De acordo com Chauí (2003, p. 6), "essa localização da educação no setor de serviços não exclusivos do Estado significou: a) que a educação deixou de ser concebida como um direito e passou a ser considerada um serviço; b) que a educação deixou de ser considerada um serviço público e passou a ser considerada um serviço que pode ser privado ou privatizado". Ainda conforme a autora, "a reforma do Estado definiu a universidade como uma organização social e não como uma instituição social. [...] A instituição social aspira à universidade. A organização sabe que sua eficácia e seu sucesso dependem de sua particularidade. Isso significa que a instituição tem a sociedade como seu princípio e sua referência normativa e valorativa, enquanto a organização tem apenas a si mesma como referência, num processo de competição com outras que fixaram os mesmos objetivos particulares".
} 
tipo: corrente de oração (prayer chain), mensagem de petição (email petition), mensagem fraudulenta (email hoaxing), etc.

$\mathrm{Na}$ materialidade linguística do exemplo 2, pode-se perceber o desinteresse pela mensagem eletrônica anterior, o que, inicialmente, é sinalizado pela ausência de interlocução direta com o autor da mensagem, pois não há uso do vocativo, constituinte linguístico bastante comum ao gênero e-mail, ainda que não seja obrigatório. A autora assina o e-mail com o nome completo, além de antecedê-lo com a forma linguística de função pronominal Profa., diferentemente do exemplo 1, em que o autor assina apenas com o primeiro nome. Esse registro se configura como um indício do limite espacial pontilhado dentro do campo de forças em conflito, onde o individualismo se sobrepõe aos "problemas compartilhados" (BAUMAN, 2003, p. 129). A forma linguística utilizada como fechamento da interlocução (Boas discussões.) contribui para construção da ironia presente no texto, além de se configurar como uma forma de saída definitiva da autora da interação instaurada. A pertinência dessa interpretação se fortalece quando se tem acesso ao terceiro e-mail da sequência interlocutiva, produzido por outro doutor em História, que informa diretamente à docente que o e-mail dela seria retirado da lista.

A ausência da interpelação direta, associada ao uso da forma verbal na primeira pessoa do plural, além dos aspectos contextuais, parece estabelecer uma interlocução com os demais docentes da lista de e-mail institucional. A ênfase na interlocução por meio do uso da sentença interrogativa (o que faz̧emos com email indesejáveis?), após um enfático $O k$, corrobora a construção da ironia na mensagem eletrônica. A resposta atribuída à própria sentença interrogativa elaborada evidencia maior força enunciativa (SPAM!), tanto pela carga semântica da palavra, lixo eletrônico, quanto pelo uso de letras maiúsculas, caixa alta, seguidas do sinal de exclamação. As letras maiúsculas são bastante utilizadas nas interações em ambientes virtuais para indicar aumento na altura da voz ou, até mesmo, grito. Ainda focalizando diretamente os aspectos linguísticos dos e-mails exemplificados, destaco que a escrita de ambos "tende a uma certa informalidade, menor monitoração e cobrança pela fluidez do meio e pela rapidez do tempo" (MARCUSCHI, 2004, p. 29). 
Inicialmente, diria que a mensagem eletrônica inicial foi recebida como lixo eletrônico por causa da manifestação explícita de posicionamento político, situação caracterizada por Marcuschi (2004, p. 59) como um "desvirtuamento" do papel do gênero lista de discussão. Mas a troca de e-mail aqui analisada realmente se configuraria numa lista de discussão ou fórum? Poderia atribuir uma resposta negativa a esse questionamento, pois os proprietários dos endereços eletrônicos não ingressaram espontaneamente nessa que seria uma comunidade virtual formada por docentes de um campus universitário, portanto, não há interesses comuns definidos pela suposta comunidade. $\mathrm{Na}$ interação focalizada, não identifiquei uma pessoa exercendo a função de moderador ou webmaster, conforme é comum nas listas de discussão ou nos fóruns virtuais. Conforme Marcuschi (2004, p. 58), essa figura "direciona as mensagens e faz a triagem, pois pode ocorrer de alguns participantes inoportunamente remeterem mensagens que não cabem na lista, seja por razões éticas, políticas ou outras quaisquer".

Definitivamente, não encontro argumentos suficientes para sustentar a tese de que a troca de mensagens eletrônicas, analisada neste trabalho, configure-se no gênero lista de discussão. Os dados analisados revelam servidores públicos se apropriando de um artefato tecnológico para interagir num novo espaço, o ambiente profissional virtual. Tal apropriação é perpassada por relações de forças, ideologias e interesses particulares. A interação no ambiente profissional virtual parece influenciada por outras interações mediadas pela tecnologia eletrônica, em ambientes virtuais não profissionais, as quais, conforme Bauman (2005, p. 101), estão substituindo os relacionamentos presenciais sólidos com pessoas reais. Sobre o individualismo nas trocas de mensagens eletrônicas entre grupos de usuários, Violi (2009, p. 57) apresenta o seguinte comentário:

Mesmo que as mensagens por correio eletrônico possam ser enviadas a diversos usuários ao mesmo tempo, elas não deixam de ser um sistema de comunicação altamente 'individualista', o que não facilita a comunicação de grupo, mas, ao contrário, induz à fragmentação do diálogo no tipo de trocas um-a-um ou um-atodos, mais centrado no remetente do que na interação. 
O uso do e-mail institucional não está regulamentado institucionalmente, restando, portanto, aos servidores públicos se utilizarem de regras e práticas que compõem o código moral por eles compartilhado. Considerando que o conceito de moral é bastante incerto, ou melhor, relativo, envolvendo alguns conceitos até contraditórios, como autonomia, desejo, emoção, integridade e razão (FURROW, 2007), o conflito tende a ser inerente à prática profissional em construção. No próprio "Código de Ética Profissional do Servidor Público Civil do Poder Executivo Federal" há passagens bastante marcadas pela atribuição de autonomia ao servidor para agir dentro da integridade esperada da administração pública, conforme pode ser observado na Alínea III, quando é afirmado que "o equilíbrio entre a legalidade e a finalidade, na conduta do servidor público, é que poderá consolidar a moralidade do ato administrativo".

\section{ESPECIFICIDADES DO GÊNERO E-MAIL}

Nos estudos linguísticos, a produção acadêmica sobre gêneros discursivos é bastante significativa, compreendendo, inclusive, os gêneros que circulam em ambientes virtuais, denominados "gêneros textuais emergentes" (HEYD, 2004; MARCUSCHI, 2004) ou "egêneros" (SOUZA, 2010). Para Marcuschi (2004, p. 30), um "aspecto reiteradamente salientado na caracterização dos gêneros emergentes é $o$ intenso uso da escrita, dando-se praticamente o contrário em suas contrapartes nas relações interpessoais não virtuais" (grifo do autor).

Sobre as mensagens eletrônicas, uma primeira questão que se apresenta nos trabalhos científicos é se o e-mail seria gênero ou canal. Para essa questão, concordo com Paiva (2004, p. 76) ao afirmar que "pelo correio eletrônico circulam vários gêneros (ofício, abaixo-assinado, receitas culinárias, propagandas), mas defendo que existe um gênero específico associado a esse novo artefato". Nessa perspectiva, a exclusão de uma das alternativas postas não parece ser a melhor opção. Neste trabalho, utilizo-me do duplo enfoque: nos outros gêneros, quando o $e$ mail funciona como um canal de circulação de textos, como um software, caracterizado como um suporte dos gêneros; e no próprio corpo da mensagem eletrônica, quando o e-mail é tomado enquanto um gênero, 
materializado em textos. Antecedente do e-mail, o gênero carta impressa, agregado ao envelopamento, também pode englobar vários gêneros, como aviso, condolência, convite, fotografia, ofício, etc. Acredito, portanto, que a carta impressa pode oferecer possibilidades de circulação de outros gêneros, assim como concebido o gênero e-mail neste artigo científico.

Sintetizo duas teses recorrentes em estudos linguísticos propostos para descrever o gênero e-mail. Ao afirmar que "o e-mail gerou uma revolução nas relações humanas”, Paiva (2004, p. 89) apresenta uma conclusão comum aos trabalhos mencionados. Essa primeira tese poderia ser posta de forma mais complexa: o próprio e-mail está inserido num fluxo de ações, desencadeadoras de inúmeras revoluções, portanto tal artefato tecnológico também é fruto da transformação pela qual passa a sociedade pós-moderna. A revolução a que se refere a autora é provocada por alguns atributos desse gênero, a saber: "a fragmentação de nossos diálogos, a distância entre os participantes, a desmaterialização de nossa escrita, ao lado da construção de um efeito de contemporaneidade na troca" (VIOLI, 2009, p. 59).

A interação assíncrona permite a tematização de questões que dificilmente seriam postas numa conversação convencional, pois, por não haver diálogo face a face, os interactantes sentem-se menos receosos para expressar os próprios posicionamentos, podendo gerar discussões bastante tensas. Por não haver um documento legal que regulamente $\mathrm{o}$ uso desse espaço público virtual, na instituição focalizada, conforme discutido na seção anterior, os servidores públicos se utilizam das regras e práticas que compõem o código moral que acreditam compartilhar. $\mathrm{O}$ e-mail é um autêntico produto da "modernidade líquida", caracterizada, na situação focalizada, pela perda dos vínculos firmes entre profissionais que se desejam "conectados" em função do pleno funcionamento da instituição pública em que são servidores. Conforme Bauman (p. 2005, p. 100), "hoje em dia, nada nos faz falar de modo mais prazeroso do que as 'redes' de 'conexão' ou 'relacionamento', só porque a 'coisa concreta' as redes firmes entretecidas, as conexões firmes e seguras, os relacionamentos plenamente maduros - praticamente caiu por terra".

A segunda tese a ser apresentada corresponde ao estilo linguístico bastante informal característico das mensagens eletrônicas, conforme mencionado na seção anterior deste artigo e destacado por inúmeros 
trabalhos que focalizam a escrita em ambiente digital (MARCUSCHI, 2004; PAIVA, 2004; VIOLI, 2009; WOLLMAN-BONILLA, 2003; só para citar alguns). A escrita digital característica do gênero e-mail é orientada por convenções próprias, chegando a ser situada num lócus intermediário entre as formas de comunicação oral e escrita, podendo se aproximar desses extremos conforme a interlocução estabelecida (VIOLI, 2009, p. 54).

Pelo distanciamento da escrita convencional, Wollman-Bonilla (2003, p. 128) compara o gênero e-mail a uma conversa escrita. Nessa perspectiva, a autora afirma que "mensagens de correio eletrônico refletem linguagem informal e abreviada e são geralmente menos explícitas e elaboradas do que o texto escrito tradicional, o que é motivado pela suposição de envolvimento e proximidade compartilhada" pelos interactantes 9 . O e-mail configura-se como um ambiente virtual pouco convencional para reprodução da ordem ou regulamentação linguística, orientada por práticas de letramento escolar, legitimadoras do propagado mito do único padrão linguístico a ser seguido.

O estilo linguístico característico do e-mail fica bastante evidente na pesquisa sobre letramento realizada por Wollman-Bonilla (2003), quando relata a apropriação da língua escrita por uma criança de 6 anos. Ao comparar o estilo dos e-mails e das cartas produzidas pela criança, a autora percebeu a apropriação espontânea, nos eventos de letramento ${ }^{10} \mathrm{em}$ que estava envolvida a pequena Rosa, dos estilos linguísticos adequados à escrita dos dois gêneros. Não houve sobreposição das convenções linguísticas características dos gêneros, mas respostas adequadas às situações de interação espontânea de que participou a criança. Nas palavras da autora, "a velocidade relativa de comunicação por correio eletrônico pode encorajar a produção de mensagens rápidas, breves, como turnos numa conversação, em vez do ritmo mais lento e mais cuidado, associado a uma carta manuscrita ${ }^{11}$ (WOLLMAN-BONILLA, 2003, p. 127).

\footnotetext{
9 "As written conversation, e-mail messages reflect informal, abbreviated language and are generally less explicit and elaborated than traditional written text because of the assumption of shared involvement and immediacy" (WOLLMAN-BONILLA, 2003, p. 128).

${ }^{10}$ Eventos de letramento são as atividades particulares em que a escrita tem um papel, são atividades recorrentes numa sociedade (BARTON, 1994, p. 37).

11 "The relative speed of e-mail communication might encourage quick, brief, off-the-cuff messages like turns in a conversation, rather than the slower pace and more deliberate care associated with handwriting a letter" (WOLLMAN-BONILLA, 2003, p. 127).
}

SILVA - Regulamentação linguística em e-mails institucionais... 
As mensagens eletrônicas aqui investigadas são produtos de uma interface bastante semelhante às provocadas pelos softwares de e-mails convencionais, tomados aqui como caracterizadores de um contexto cultural mais amplo, trazendo, portanto, esses elementos da escrita menos elaborada. Além das marcas desse contexto, as referidas mensagens são informadas diretamente por um contexto situacional imediato, na esfera da universidade pública brasileira, marcada por relações profissionais que exigem maior formalidade. No cruzamento desses dois contextos, as trocas de e-mails, no ambiente profissional virtual, provocaram conflitos em torno dos usos das formas linguísticas, conforme passo a analisar diretamente na próxima seção.

\section{EMBATE NA ESCRITA UNIVERSITÁRIA}

As regras e práticas componentes do código moral, compartilhado por docentes da universidade aqui focalizada, não foram suficientes para suprir a falta de regulamentação do uso do software do e-mail institucional. Até mesmo o código de ética, a que fiz referência no final da segunda seção deste artigo, parece ignorado nas trocas de mensagens eletrônicas. Ou seja, a "harmonia", o "respeito" e a "cooperação", atributos comuns à "estrutura organizacional", nas diferentes interações convencionais, no espaço físico de trabalho do servidor público, são esquecidos na interação instaurada no ambiente institucional virtual, conforme mostro a partir do e-mail reproduzido no exemplo 3. A alínea XIII do "Código de Ética Profissional do Servidor Público Civil do Poder Executivo Federal" reza que "o servidor que trabalha em harmonia com a estrutura organizacional, respeitando seus colegas e cada concidadão, colabora e de todos pode receber colaboração, pois sua atividade pública é a grande oportunidade para o crescimento e o engrandecimento da Nação".

$\mathrm{Na}$ escrita acadêmica, o embate se intensifica a partir da quarta mensagem eletrônica enviada, exemplo 3, quando um dos interlocutores, Sivirinu, mestre em Geografia, autor da epígrafe deste artigo, toma a palavra espontaneamente para manifestar a própria opinião diante da segunda mensagem enviada, produzida pela Profa. Clara Maria Sousa Silva e analisada na segunda seção deste trabalho. 


\section{Exemplo 3 - E-mail 4}

Lamentável a opinião e de alguns docentes. Será que estão mesmo no lugar certo ? Numa universidade ? Onde as discursões a respeito do destino do país é pauta e prioridade ?

Sinceramente, alguns colegas deveriam estar onde apenas dizem "sim senhor, ou sim senhora".

Paciencia colegas,

Repito, independente do posicionamento político é bom sabermos quem de fato está aberto a discursões ou quem se omite dos compromissos fundamentais do que de fato é ser profissional de educação numa U N I V E R S I D A D E.

Abraços,

O exemplo 3 configura-se como a mensagem mais espontânea do corpus aqui analisado, trazendo muitas das características do gênero, identificadas pelos estudos linguísticos, os quais, é importante destacar, não consideram as especificidades do software institucional. Além da ausência de vocativo e da assinatura do interlocutor, e do uso de construções sintáticas curtas e da caixa alta para fortalecer o ato enunciativo, a espontaneidade é marcada pelo uso bastante expressivo da pontuação em conformidade com o conhecimento que se compartilha do estilo característico do gênero e-mail convencional. Conforme destaca Violi (2009, p. 58), “o processo de escrita do e-mail é muito peculiar no sentido de que ele é completamente desmateriazalizado: mesmo a assinatura, a marca final de um escritor específico e único, desaparece, substituída pela imaterialidade de um endereço de e-mail, incluído por default em qualquer mensagem" (itálico da autora).

O exemplo 3 questiona a função do docente na universidade pública, considerando, portanto, o próprio papel da universidade na sociedade em que está inserida. O geógrafo destaca que "as discursões a respeito do destino do país é pauta e prioridade" na universidade pública, posicionamento que vai ao encontro de críticas produzidas à concepção de universidade como organização, imposta pela reforma neoliberal do Estado de que fala Chaú (2003, p. 6), ao afirmar que, reduzida a uma organização, à universidade não "compete discutir ou questionar sua própria existência, sua função, seu lugar no interior da luta de classes". Ainda nos termos da autora, "reduzida a uma organização, a universidade abandona a formação e a pesquisa para lançar-se na 
fragmentação competitiva" (CHAUÍ, 2003, p. 8). O uso marcado por aspas de outras vozes ("sim senhor, ou sim senhora") caracteriza uma postura do servidor público semelhante ao que se observa em instituições privadas, regidas pelas ideias de "gestão, planejamento, previsão, controle e êxito” (CHAUÍ, 2003, p. 3).

Nessa quase sincronia da interação focalizada, em que as quatro primeiras mensagens eletrônicas da sequência interativa analisada circularam num único dia, os desvios ortográficos e gramaticais, considerando as prescrições apresentadas nos inúmeros manuais existentes de correção linguística, destacando-se, dentre eles, as gramáticas normativas ${ }^{12}$, tornam-se frequentes e característicos nos denominados e-gêneros. Reproduzindo um confronto histórico entre diferentes áreas do conhecimento, perpassado por escolhas epistemológicas num mercado autorregulado, conforme sintetizado na introdução deste artigo, os docentes focalizados se "utilizam" de um suposto padrão linguístico, pautado nas mencionadas gramáticas normativas, para questionar a competência profissional dos seus pares, outros docentes também admitidos por meio de concurso público na universidade.

No exemplo 4, reproduzo a mensagem eletrônica de Pedro Oliver Alburquerque Andrade, doutor em Zootecnia, profissional bastante respeitado na instituição pela experiência acadêmica trazida de outra universidade pública, na qual também realiza atividades de pesquisa científica. Esse profissional tem contribuído de forma muito significativa para o desenvolvimento da pós-graduação stricto sensu na universidade, como a implementação do único curso de doutorado da instituição, na área das ciências agrárias. Aqui, focalizo especificamente a reflexão metalinguística presente na mensagem eletrônica produzida por esse servidor público.

\footnotetext{
${ }^{12}$ Conforme Bagno (2000, p. 39), "as gramáticas foram escritas precisamente para descrever e fixar como 'regras' e 'padrões' as manifestações linguísticas usadas espontaneamente pelos escritores considerados, numa determinada época, dignos de admiração, modelos a ser imitados. Ou seja, a gramática normativa é decorrência do uso da língua, é subordinada a ele, dependente dele. Como a gramática normativa, porém, passou a ser um mecanismo ideológico de poder e de controle de uma classe social dominante sobre as demais, surgiu essa 'falsa consciência', esse 'senso comum', essa 'base real de ponta-cabeça' de que os falantes e escritores da língua é que precisam da gramática normativa, como se ela fosse uma espécie de fonte mística invisível da qual emana a língua 'bonita', 'correta' e 'pura'. A língua passou a ser subordinada e dependente da gramática normativa. O que não está na gramática normativa 'não é português”' (grifos do autor).
} 


\section{Exemplo 4-E-mail 5}

Caros Colegas

Inicialmente gostaria de esclarecer que votarei na Dilma em função de ter vivido o mais triste momento das IFES no governo FHC e temer que o Paulo Renato volte a ser ministro da educação.

Tenho recebido inúmeros e-mail onde o tema é Dilma x Serra. Fico bastante triste em vir que vários colegas demitiriam professores pelo fato de não estarem preparados para conviver e servir no meio universitário.

É nesse momento que acho que a discussão sobre o tema é inválida. Fico triste com tanta troca de farpas. Não acho que sairemos maior desse processo. Fico mais triste ainda com os erros de ortografia e concordância que campeiam essas mensagens. Esses talvez devessem ter a admissão na Universidade reavaliada.

Atenciosamente

Pedro Oliver Albuquerque Andrade

Os "erros de ortografia e concordância", encontrados nos e-mails previamente enviados, são descritos, no exemplo 4, como elementos responsáveis pela tristeza manifestada pelo docente diante da interação virtual instaurada (Fico mais triste ainda com os erros de ortografia e concordância que campeiam essas mensagens). As formas adverbiais mais e ainda contribuem para intensificar o sentimento expresso pelo docente diante dos "erros" encontrados nos textos. Ainda que modalizadamente, pelo uso da forma adverbial talvez, e pela escolha do modo verbal subjuntivo (devessem), a inobservância das prescrições linguísticas, mesmo num gênero que admite usos linguísticos mais flexíveis, é apresentada como motivo mais significativo para reavaliação da admissão de docentes na universidade pública.

Ao discutir sobre a reprodução da discriminação e do poder nas atividades de linguagem, Gnerre (2003, p. 6) destaca que "a língua padrão é um sistema comunicativo ao alcance de uma parte reduzida dos integrantes de uma comunidade; é um sistema associado a um patrimônio cultural apresentado como um 'corpus' definitivo de valores, fixados na tradição linguística”. Com os dados trazidos nesta pesquisa, parece-me que o alcance da língua padrão só é possível a uma parte muito mais reduzida dos falantes nativos da língua portuguesa utilizada 
no Brasil, uma vez que nem os mestres e doutores, diante de uma população de mais de 185 milhões de brasileiros, conseguem se adequar às prescrições linguísticas subjacentes a esse padrão ${ }^{13}$.

No exemplo 5, o historiador responsável pelo envio da mensagem inicial, agora assinando o nome completo, na tentativa de produzir uma escrita mais formal, encapsula o posicionamento explicitado pelo zootecnista, autor da mensagem anterior, com a expressão nominal semialfabetizados. Essa expressão foi utilizada para se referir aos mestres e doutores que parecem não adequar suas mensagens eletrônicas à língua escrita padrão. Diante dos demais interlocutores que apenas acompanham o embate, por não se manifestarem enviando mensagens, $o$ historiador interpela diretamente o zootecnista para explicitar que o docente também cometeu os mesmos "erros" motivo do desapontamento manifestado por ele mesmo diante da escrita das mensagens anteriores.

\section{Exemplo 5 - E-mail 6}

Prof. Pedro,

Um professor já disse nessas discussões que mantemos aqui que os seus colegas da UFWX não trabalham, o sr. diz agora que alguns parecem ser semi-alfabetizados, mesmo sendo mestres e doutores; e que esses mesmos professores deveriam - foi o que entendi - ter a sua admissão na Universidade reavaliada. Fico pensando aqui no meu silêncio que do mesmo modo que alguns colegas, na ânsia de argumentar, incorrem em erros de ortografia e concordância, o sr., também ansioso por expressar seu descontentamento, não pecou na avaliação. Sinceramente não é possível supor que o sr. acredite nisso. Pois lamentável seria um professor universitário que pensasse assim!

Att

Paulo Roberto Tavares Filho

P.S Fiz várias leituras dessa mensagem. Se cometi algum erro de concordância e ortografia me avisem. Eu prometo resolver num e-mail seguinte.

\footnotetext{
${ }^{13}$ Esse número corresponde ao Censo 2010, publicado no Diário Oficial da União, em 04/11/2010. Disponível em: <http://www.censo2010.ibge.gov.br/dados_divulgados/index.php?uf=00>. Acesso em: 19 maio 2011.
} 
No exemplo 5, o historiador tenta mostrar uma contradição na exposição do zootecnista, caracterizada pela impossibilidade de existência de mestres e doutores semialfabetizados. Até alcançar os títulos de mestre e de doutor, esses profissionais passam por diversas situações acadêmicas em que precisam provar competência por meio do uso da produção textual escrita, culminando com a apresentação final de um trabalho acadêmico bastante elaborado - dissertações e teses -, resultado da pesquisa científica realizada.

$\mathrm{Na}$ escrita do historiador, as reflexões metalinguísticas sobre o gênero e-mail são bastante significativas, pois podem justificar o uso da escrita menos vigiada, convencional em algumas situações interativas, características do ambiente virtual. As expressões "na ânsia de argumentar" e "ansioso por expressar seu descontentamento" faz-me lembrar da conversa escrita, comparada ao e-mail, a que faz referência Wollman-Bonilla (2003), ao discutir a expectativa do usuário, criada pelo artefato digital, em obter respostas para as mensagens eletrônicas enviadas num espaço de tempo muito curto, o que impossibilita um cuidadoso planejamento da escrita no ambiente virtual, diferentemente das práticas de letramento características da cultura do texto impresso. Provavelmente de forma inconsciente, o historiador focaliza algumas convenções estilísticas características do gênero, ou seja, o e-mail prestase à informalidade linguística, mesmo no âmbito institucional.

Ainda no exemplo 5, observo o uso do Post Scriptum (P.S), recurso linguístico característico dos gêneros epistolares, que permaneceu nas mensagens eletrônicas. Utilizando esse recurso, o historiador explicita um comportamento atípico na interface com o software institucional, que é o excesso de zelo com a escrita digital (Fizv várias leituras dessa mensagem. Se cometi algum erro de concordância e ortografia me avisem. Eu prometo resolver num e-mail seguinte.), conforme fica evidente na própria mensagem eletrônica, quando se menciona o imediatismo da troca de e-mail. Esse zelo na escrita é justificado pelas coerções sofridas nas trocas de mensagem.

Para finalizar a análise dos dados de pesquisa, focalizo simultaneamente o exemplo 6, produzido por Sivirinu, geógrafo, e o exemplo 7, produzido por Pedro, zootecnista, reproduzidos abaixo. Continuo insistindo nas adequações linguísticas reguladas pelos gêneros, as quais são tematizadas nas reflexões metalinguísticas realizadas pelos 
docentes nas mensagens eletrônicas trocadas. Sob pressão, os docentes se utilizam do conhecimento linguístico que detêm e mobilizam outros gêneros como forma de (inter)ação, tornando perceptível para os interlocutores que eles, diferentemente do mostrado na "troca de farpas", utilizam-se da agentividade para trabalhar com e sobre a escrita, pois tiram proveito, inclusive, da variação linguística para dar expressividade ao texto. Conforme Signorini (2011, p. 209), também concebo agentividade como "uma dimensão ou vetor resultante das 'orientações agentivas' variáveis dos atores sociais no curso de suas ações, e não uma capacidade mais ou menos racional, mais ou menos livre, mais ou menos consciente, das ações verbais numa dada situação"14.

\section{Exemplo 6 - E-mail 11}

CAros Colegas,

PAssada as eleições, fiz NU MOMENTO DE LAZER, pelo amor de D-us não me acusem de NÃO FAZER NADA, nem me mandem trabalhar... amanhã, quarta feira $(03 / 11 / 2010)$ estarei à postos...

Ressalto só a cultura popular do Nordeste.

Qui estão os meus VÉUSSUS ${ }^{15}$

Exemplo 7 - E-mail 12

Caro Colega Sivirinu

Gostei muito dos seus versos. São por demais trabalhados. Sinceramente.. Gostei. Infelizmente não posso aceitar o "desafio" pois repente não é a minha praia. No entanto gosto muito de escrever. Acho que o bom seria que usássemos a poesia para nos aproximar, para falar de nossas dores. É por isso que não gosto muito do repente pois sempre alguem sai perdendo.

Faço poesia, com erros de português tambem....

\footnotetext{
${ }^{14}$ Ainda conforme a autora, "os atores sociais estão sempre reavaliando e recompondo objetivos e meios já dados ou emergentes num dado 'contexto temporal-relacional de ação', em função de seus repertórios individuais e coletivos, conscientes (memória) ou não (padrões habituais de ação e pensamento; memória corporal), e suas capacidades de imaginação, reflexão, hipotetização etc., em resposta às mudanças situacionais que vão surgindo" (SIGNORINI, 2011, p. 209).

${ }^{15}$ Com a autorização do autor, substituí os nomes próprios mencionados na versão original dos versos produzidos, assim como procedi nos demais exemplos reproduzidos neste trabalho (ver Texto 1 nos Anexos).
} 
A última que fiz foi num momento de muita dor. No dia 07 de outubro perdi a minha mãe e rabisquei umas linhas prá ela. Segue em anexo só para voce vir que não tem cabimento nos desafiarmos. Trabalhamos na mesma instituição, moramos na mesma cidade, talvez busquemos os mesmos objetivos. Aí uma eleição onde votamos na mesma candidata torna essa coisa desagradável... Não vou mais responder as mensagens do fórum pois virou um briga...

Segue a minha poesia. Sem desafio.. Sem ressentimentos.

Espero que todos nós aceitemos sim; o desafio de tornar a UFWX maior. Eu já o aceitei há muito tempo.

Obrigado por tudo e se ofendí alguem.... Desculpa... Acho que não tem mais cabimento esse tipo de troca de farpas...

Quem tiver tempo, leia minha poesia... Tenho outras já publicadas. Mas não servem para desafios..

Abraços

Pedro

Após a eleição presidencial, a mensagem eletrônica reproduzida no exemplo 6 provoca a retomada da interação temporariamente interrompida. No próprio corpo da mensagem, o autor apresenta o que é por ele denominado VÉUSSUS (ver Texto 1 nos Anexos), os quais sintetizam integralmente a interação no ambiente virtual institucional. $\mathrm{O}$ estilo linguístico do gênero é expressivamente explorado com a caixa alta, enfatizando algumas partes do texto que dialogam com mensagens trocadas previamente, como as passagens NU MOMENTO DE LAZER e $N \tilde{A O}$ FAZER $N A D A$, utilizadas para evitar críticas dos interlocutores ou respostas por meio do próprio software institucional. Conforme o autor, os VÉUSSUS não foram produzidos durante o expediente, evitando a acusação de utilizar o horário do serviço público para atividades que fogem ao interesse da instituição, diferentemente da troca de mensagens eletrônicas, conforme insinuações nos textos aqui analisados.

Os VÉUSSUS se configuram num gênero literário da cultura popular do Nordeste, como ressalta o próprio autor. Lembram o repente nordestino, crônica poética utilizada para desafiar pessoas a produzirem versos musicalizados sobre acontecimentos vivenciados pela sociedade, revelando o imaginário popular. Nesse gênero, Sivirinu parece autorizado 
a ignorar a língua padrão, reproduzindo, talvez, até mesmo, de forma artificializada, uma dada variedade linguística característica da conhecida oralidade nordestina (Que escreve esses véussus/Errados no linguajâ). Dentro do jogo linguístico dos VÉUSSUS, há irregularidades que parecem escapar ao controle do próprio autor, como a oscilação do uso do $r$ final, nas construções verbais compostas (ouvi falá, veio chegá, sei escrevế; vou irritar, Devem estar, deveria estar). Com os VÉUSSUS, o geógrafo desafia o zootecnista, que revela gostar de textos em versos, pois a poesia possibilitaria, conforme explicitado no exemplo 7 , a aproximação entre as pessoas e a tematização das dores pessoais (o bom seria que usássemos a poesia para nos aproximar, para falar de nossas dores).

O exemplo 7 corresponde à última mensagem eletrônica circulada entre os docentes (Não vou mais responder as mensagens do fórum pois virou um briga....). Nessa mensagem, o zootecnista recusa o desafio do repente, mas se utiliza do recurso Anexos, disponibilizado pelo software, para anexar um poema, produzido pelo docente em homenagem à própria mãe, falecida no mês anterior à época da interação focalizada (ver Texto 2 nos Anexos). A recusa do desafio é justificada pela aparente eliminação da fronteira no espaço social organizado por grupos de professores representando áreas distintas de conhecimento, os quais parecem compartilhar interesses particulares sobrepostos aos institucionais mais amplos (não tem cabimento nos desafiarmos. Trabalhamos na mesma instituição, moramos na mesma cidade, talvez busquemos os mesmos objetivos. Ai uma eleição onde votamos na mesma candidata torna essa coisa desagradável...). Essa última mensagem traz pedidos de desculpas e agradecimentos; até mesmo o fechamento do texto é marcado por uma despedida mais cortês (Abraços), seguida da assinatura apenas com o primeiro nome, registros não encontrados nas mensagens anteriores do zootecnista. Refiro-me à aparente eliminação das fronteiras porque, no momento final da mensagem, continuam ecoando as vozes reveladoras do embate no permanente campo de forças, no qual são contrapostos: os textos $\mathrm{com} / \mathrm{sem}$ desafio e ressentimento; e os docentes que trabalham/não trabalham ou que já aceitaram o desafio/ainda não aceitaram o desafio (Segue a minha poesia. Sem desafio.. Sem ressentimentos. Espero que todos nós aceitemos sim; o desafio de tornar a UFWX maior. Eu já o aceitei há muito tempo). 
Finalmente, focalizando mais diretamente a regulamentação linguística, a análise revela que a interação no ambiente virtual profissional desencadeou diferentes reflexões metalinguísticas, deixando os participantes diretos da interação mais sensíveis às adequações linguísticas a serem feitas conforme as situações enunciativas. O próprio autor do questionamento que atrelava "os erros de português" à competência dos professores universitários, finalmente, admite cometer tais "erros": Faço poesia, com erros de português também... Os gêneros tiveram um papel decisivo nessa sensibilização dos docentes, afinal "não apenas ajudam pessoas reais, em comunidades espaço-temporais, a fazer seu trabalho e realizar seus propósitos; eles também ajudam as comunidades virtuais - as relações que carregam em nossas mentes - a responder e reconstruir a si mesmas para continuarem suas histórias" (MILLER, 2009, p. 58).

\section{CONSIDERAÇÕES FINAIS}

Nos dados analisados, representativos de outros registros que cuidadosamente arquivei, em diferentes situações de uso do software de $e$ mail institucional, verifiquei a configuração do que denominei, neste trabalho, espaço institucional virtual, para o qual, na universidade focalizada, ainda não foram convencionadas regras precisas de uso. Pela ausência dessas regras, parecem vigorar as convenções das interações virtuais consolidadas, como as utilizadas nos e-mails convencionais, não necessariamente informadas pelos princípios norteadores do serviço público federal.

No e-mail institucional, a adequação dos usos das formas linguísticas à escrita formal parece compartilhada pelos usuários do serviço público, pois, na comunicação mediada por documentos institucionais impressos, a escrita formal é observada. $\mathrm{Na}$ troca das mensagens eletrônicas analisadas, o uso do espaço institucional virtual para propaganda política, sem a adesão de todos os servidores públicos que estavam na lista de e-mail, parece ser a causa do conflito instaurado. Por a propaganda não se configurar como documento institucional, provavelmente houve a motivação para o uso da escrita informal, característica das interações virtuais convencionais, o que não foi compreendido e aceito por alguns docentes, comprometidos com outros

SILVA - Regulamentação linguística em e-mails institucionais... 
interesses. Esses docentes apropriaram-se discursivamente da norma padrão da língua como mecanismo de poder, ainda que não tenham conseguido se apropriar da referida norma na escrita das próprias mensagens eletrônicas produzidas. Alguns desvios da norma encontrados nos dados analisados talvez não sejam motivados pelo ambiente virtual, mas ocorreriam, atém mesmo, em documentos impressos. Porém, para apresentar alguma conclusão mais precisa a esse respeito, seria necessário analisar a escrita dos autores das mensagens eletrônicas em contextos não virtuais.

No embate instaurado em torno da ordem ou da regulamentação linguística, os interlocutores subordinam, inicialmente, a língua escrita à gramática normativa, utilizada como mecanismo ideológico de poder por profissionais que parecem desejar a legitimação de autoridade, nas relações institucionais, para subcomunidades ou subgrupos por eles representados, num espaço social dividido. No segundo momento, os docentes parecem chegar ao consenso de que a interação seria reduzida à "troca de farpas", caso insistissem na utilização dos usos das formas linguísticas para desqualificar os pares. A reorientação do conteúdo interacional parece evitar o mais provável desfecho: a desqualificação de todos os docentes envolvidos na interação. Assim como qualquer usuário da língua mais ou menos escolarizado, não conseguiram escapar ao curso natural das adequações sofridas pelo uso das formas linguísticas nas diferentes situações interativas e, em especial, no ambiente virtual, o qual passa por significativas e rápidas transformações motivadas pelo acelerado e impactante desenvolvimento tecnológico.

Como muitos serviços na Internet, os usuários da rede estão se familiarizando com as constantes inovações nos recursos disponíveis no espaço virtual, o que não é diferente com os softwares responsáveis pela circulação de mensagens eletrônicas. Considerando ainda os mais diversos usos que podem ser feitos desse artefato digital, envolvendo a assustadora força de propagação de informações, com alcance imensurável, as mensagens eletrônicas podem ser utilizadas como munição para o favorecimento de interesses particulares ou de pequenos grupos.

Por meio de mensagens eletrônicas, além dos usos mais produtivos (como a troca de informações dentro de grupos virtuais com interesses comuns ou as frequentes petições públicas que circulam nas 
caixas de e-main), são realizadas denúncias a partir da circulação de informações das quais, quase sempre, não se pode assegurar a legitimidade da fonte. Para alguns usuários da Internet, as informações que circulam nessas mensagens são aceitas sem desconfiança, evidenciando alguns resquícios de mitos do letramento, como se a apresentação da informação na modalidade escrita da língua blindasse a legitimidade do conteúdo. O uso irresponsável do e-mail para circulação de mensagens eletrônicas desse tipo pode provocar prejuízos irreparáveis a qualquer cidadão. Muitas das questões pontuadas neste parágrafo final ainda precisam ser investigadas com profundidade a partir de uma diversidade maior de dados. Este artigo configura-se como o primeiro momento de uma ampla pesquisa iniciada recentemente.

\section{REFERÊNCIAS}

BAGNO, M. Dramática da língua portuguesa: tradição gramatical, mídia \& exclusão social. São Paulo: Edições Loyola, 2000.

BARTON, D. Literacy: An introdution to the ecologia of written language. Oxford: Blackwell, 1994.

BAUMAN, Z. Identidade. Rio de Janeiro: Jorge Zahar, 2005.

Comunidade: a busca por segurança no mundo atual. Rio de Janeiro: Jorge Zahar, 2003.

BOURDIEU, P. Razões práticas: sobre a teoria da ação. 3. ed. Campinas: Papirus, 2001.

CHAUÍ, M. A universidade pública sob nova perspectiva. Revista Brasileira de Educação, v. 24, p. 5-15, set./dez. 2003. Disponível em: $<$ http://www.scielo.br/pdf/rbedu/n24/n24a02.pdf>. Acesso em: 19 maio 2011.

DECRETO No 1.171, de 22 de junho de 1994. Código de Ética Profissional do Servidor Público Civil do Poder Executivo Federal. Presidência da República. Casa Civil. Subchefia para Assuntos Jurídicos.

GNERRE, M. Linguagem, escrita e poder. 4. ed. São Paulo: Martins Fontes, 2003.

MILLER, C. Estudos sobre gênero textual, agência e tecnologia. In: DIONÍSIO. A. P.; HOFFNAGEL, J. C. (Orgs.). Recife: Editora da UFPE, 2009. 
FURROW, D. Ética: conceitos chaves em filosofia. Porto Alegre: Artmed, 2007.

HEYD, T. Formal and functional characteristics of email hoaxes: a genre study, 2004. Disponível em: < http://www.ncess.ac.uk/events/conference/2007/dcpapers/Heyd_paper. pdf>. Acesso em: 17 maio 2011.

JAPIASSU, H. O sonho transdisciplinar e as razões da filosofia. Rio de Janeiro: Imago, 2006.

MARCUSCHI, L. A. Gêneros textuais emergentes no contexto da tecnologia digital. In: MARCUSCHI, L. A.; XAVIER, A. C. (Orgs.). Hipertexto e gêneros digitais. Rio de Janeiro: Lucerna, 2004. p. 13-67.

MEY, J. L. As vozes da sociedade: seminários de pragmática. Campinas: Mercado de Letras, 2001.

MILLER, C. R. Estudos sobre gênero textual, agência e tecnologia. In: DIONISIO, A. P.; HOFFNAGEL, J. C. (Orgs). Recife: Editora da UFPE, 2009.

PAIVA, V. L. M. de O. E-mail: um novo gênero textual. In: MARCUSCHI, L. A.; XAVIER, A. C.. (Orgs.). Hipertexto e gêneros digitais. Rio de Janeiro: Lucerna, 2004. p. 68-90.

SANTOS, B. de S. Um discurso sobre as ciências. 7. ed. Porto: Edições Afrontamento, 1995.

SIGNORINI, I. Estilo e agentividade na escrita. In: TFOUNI, L. V. (Org.). Letramento, escrita e leitura: questões contemporâneas. Campinas: Mercado de Letras, 2011. p. 197-215.

. Por uma teoria da desregulamentação linguística. In: BAGNO, M.

(Org.). Linguística da norma. São Paulo: Edições Loyola, 2002. p. 93-125.

SIGNORINI, I.; CAVALCANTI, M. C. Língua, linguagem e mediação tecnológica. Trabalhos em Linguística Aplicada, Campinas, v. 49, n. 2, p. 419-440, 2010.

SOUZA, A. G. Software e gênero digital: o caso do e-mail acoplado em uma plataforma WWW. In: MOURA, M. D.; SIMBALDO, M. A.; SEDRINS, A. P. (Orgs.). Novos desafios da Língua: pesquisas em língua falada e escrita. Maceió: Edufal - Editora da Universidade Federal de Alagoas, 2010. p. 343-348. Disponível em:

$<$ http://www.souza.pro.br/genero_digital_o_casodo_email.pdf $>$. Acesso em: 17 maio 2011.

VIOLI, P. O diálogo eletrônico entre a oralidade e a escrita: uma abordagem semiótica. In: BEZERRA, B. G.; BIASI-RODRIGUES, B.; CAVALCANTE, 
M. M. (Orgs.). Gêneros e sequências textuais. Recife: Editora da Universidade de Pernambuco, 2009. p. 45-60.

WOLLMAN-BONILLA, J. E-mail as genre: a beginning writer learns the conventions. Language Arts. National Council of Teachers of English, v. 81, n. 2, p. 126-134, 2003. Disponível em:

<http://stancock.iweb.bsu.edu/EDRDG445/Online/PDF/Email.pdf>. Acesso em: 17 maio 2011.

\section{ANEXO 1: TEXTO 1}

\section{Qui estão os meus VÉUSSUS}

Meus cumpadres tenho umas coisa

Para contar para vocês

Mas por favor não condenem

meus erros de português

começo esses meus veússus

com muito amor e dedicação

de uns fatos recém passados

pouco antes da eleição

numa sadia e proveitosa conversa

muita troca de informação

recebo alguma mensagens

nos tratando com humilhação

de um colega aqui estreante

por sinal nunca dele ouvi fala'

já chegou dando as ordens

mandando eu eu ir trabaiá

de onde surgiu esse hômi

que na UFWX veio chega'

tratando todos os colegas

sem ao menos nos respeita

era só um tal de fórum

que se discutia a eleição

mas o professor mandou irritado

não nos deu muita atenção 
mas o que isso meu amigo chegou humilhando a gente só purquê nós discordava em ver o Serra Presidente

Depois de alguns protesto

Numa coisa sem igual

Parabenizo pela resposta

o professor Paulo

Volto a essa conversa

Para registrar por aqui

O empenho na campanha

Feita pelo professor Valter

O distinto colega serrista

Deve estar disiludido

Ainda mandou um email

Dizendo que foi mal entendido

Não sei se li errado

O que o colega escreveu

Mas pelo que me parece

$\mathrm{O}$ analfabeto sou eu

Num pedido de desculpa

Me fez outra acusação

De te-lo entendido mal

E deu a sua versão

Mas não duvide do poeta

Que num soube lhe intendê

Mas num me encare no verssus

Que esse eu sei escrevê

Mas não vou irritar o rapaz

Deve ser um cara descolado

Mas tanto e ele e o Zé Serra

Devem estar decepcionado 
Mas a coisa não é só essa

Continuo no que se passou

Recebo outro email

Onde a coisa se alterou

Falando do erros da escrita

Nos dando uma grande lição

Que quem escreve errado

Merecia era demissão

Ô meu amigo não se irrite

Com esse poeta popular

Que escreve esses véussus

Errados no linguajá

Te peço por caridade,

Não me tire a inspiração

De ser professor universitário

Com tanta dedicação

Sei que já to errado

Nessa pobre filosofia

Eu deveria estar nas letra

E não na geografia

Mas eu convido os dois colegas

Pra uns véussus vim cantar

Mas vou logo lhe avisando

Sei como lhes desafiar

Nos veussus lá do nordeste

Sou repente sim sinhô

Mesmo escrevendo errado

Pode crer que sou doutô

Mas agora fiquei com medo

Me deu um grande pavor

Que esses meus simples véussus

Chegue até ao magnífico Reitor

Sivirinu Xique-Xique Mandacaru Aroeira

(Poeta Popular do Nordeste) 


\section{ANEXO 2: TEXTO 2}

Mainha

Tivestes sete filhos

Tal como sete

Tambem são as notas musicais.

O que seriam essas notas separadas?

Talvez apenas um som perdido no vazio do mundo.

Porém, soubeste combiná-las com grande maestria.

Fazendo as mais variadas melodias

Você foi mais que mãe!!

Você foi uma grande compositora

Que combinou-nos em variados arranjos

Fizeste melodias com notas teimosas

Ou mesmo, teimaste em melodias sem notas

Fizeste som acima do barulho da vida

Combinastes sons, filhos e notas musicais

Fizeste de nossa vida a mais pura melodia

Não podemos chorar a tua falta...

Temos que, ao modo de cada um, ouvir tua canção

Que pedes sempre para que tuas sete notas musicais

Se arranjem na mais doce harmonia

Nós vamos tentar...

Que Deus nos ilumine na sua ausência

E que te acolha com todos os seus doces acordes

Esperamos, todos; que tenhas teu merecido descanso

Confia em nós para acompanharmos nosso pai

Teu parceiro inseparável durante 52 anos

Um dia, sob o olhar divino, haveremos de nos encontrar

E viveremos eternamente sob o som de suas canções

Um beijo 
Recebido em: 07/07/11. Aprovado em: 21/01/12.

Title: Linguistic regulation in institutional emails: conflicts among university professors in the virtual institutional environment

Author: Wagner Rodrigues Silva

Abstract: We investigate metalinguistic reflexions carried out by university professors when they focus on order notions or linguistic regulations in the virtual interaction environment, in a public university. In a sociopragmatic approach, the virtual environment is characterized as a texture of social voices which signal the participants' position in the institutional space they are inserted. Analyzed data show public servants appropriating of technological artifacts to interact in a new space: the virtual professional environment. The exchange of electronic messages seems to be influenced by other interactions mediated by digital artifacts characteristic of non professional virtual environment. In this new environment such interactions seem to substitute the solid professional relationships characteristic of face-to-face interactions, minimizing the fear of focusing polemic issues towards conventional interlocutions such as the professional competence of peers oriented by the formal writing linguistic conventions, in electronic messages, exchanged in virtual institutional environment.

Keywords: Applied Linguistic. Writing. Genre. Computer literacy.

Título: Reglamentación lingüística en e-mails institucionales: Conflicto entre profesores universitários en el ambiente institucional virtual

Autor: Wagner Rodrigues Silva

Resumen: Investigo reflexiones metalingüisticas realizadas por docentes, al focalizar nociones de orden 0 de reglamentación lingüistica, en el ambiente de interacción virtual, mediado por un programa de e-mail institucional, en una universidad pública. En un abordaje sociopragmático, el ambiente virtual está caracterizado como un tejido de voces sociales, las cuales señalizan para el posicionamiento de los interactuantes en el espacio institucional en que están insertados. Los datos muestran servidores públicos apropriándose de un artefacto tecnológico para interactuar en un nuevo espacio: el ambiente profesional virtual. El c ambio de mensajes electrónicos parece influenciado por otras interacciones mediadas por artefactos digitales característicos de ambientes virtuales no profesionales. En ese nuevo ambiente, tales interacciones parecen sustituir los relacionamientos profesionales sólidos, característicos de las interacciones presenciales, minimizando el recelo del enfoque de asuntos polémicos para interlocuciones convencionales, como el cuestionamiento de la competencia profesional de los pares, orientado por la obligación de las convenciones lingüisticas de la escritura formal, en mensajes electrónicos cambiados en el ambiente virtual institucional.

Palabras-clave: Lingüistica Aplicada. Escritura. Género. Letramiento digital.

SILVA - Regulamentação linguística em e-mails institucionais... 